\title{
Designing an idea screening framework for employee-driven innovation
}

Ciriello, Raffaele Fabio ; Richter, Alexander ; Schwabe, Gerhard

\begin{abstract}
As ever more companies encourage their employees to realize innovations, a surplus of ideas that exceeds the available resources to implement them has become reality in many organizations. With this paper, we follow recent calls for designing IT-supported, comprehensive, multi-attributive idea screening throughout the whole innovation cycle. Our Idea Screening Framework is grounded in literature and empirical data we collected from a two-year field study in a multinational European banking software provider. We identify a set of dimensions for screening ideas and show with a prototype how the framework can support innovation practices by facilitating the evaluation, selection, and tracking of ideas for managers and innovators.
\end{abstract}

DOI: https://doi.org/10.1109/HICSS.2016.529

Posted at the Zurich Open Repository and Archive, University of Zurich

ZORA URL: https://doi.org/10.5167/uzh-122873

Conference or Workshop Item

Published Version

Originally published at:

Ciriello, Raffaele Fabio; Richter, Alexander; Schwabe, Gerhard (2016). Designing an idea screening framework for employee-driven innovation. In: 49th Hawaii International Conference on System Sciences (HICSS 2016), Hawaii, USA, 5 January 2016 - 9 January 2016. Institute of Electrical and Electronics Engineers, 4262-4271.

DOI: https://doi.org/10.1109/HICSS.2016.529 


\section{Designing an Idea Screening Framework for Employee-driven Innovation}

\author{
Raffaele Fabio Ciriello \\ University of Zurich \\ ciriello@,ifi.uzh.ch
}

\author{
Alexander Richter \\ University of Zurich \\ arichter@ifi.uzh.ch
}

\author{
Gerhard Schwabe \\ University of Zurich \\ schwabe@ifi.uzh.ch
}

\begin{abstract}
As ever more companies encourage their employees to realize innovations, a surplus of ideas that exceeds the available resources to implement them has become reality in many organizations. With this paper, we follow recent calls for designing IT-supported, comprehensive, multi-attributive idea screening throughout the whole innovation cycle. Our Idea Screening Framework is grounded in literature and empirical data we collected from a two-year field study in a multinational European banking software provider. We identify a set of dimensions for screening ideas and show with a prototype how the framework can support innovation practices by facilitating the evaluation, selection, and tracking of ideas for managers and innovators.
\end{abstract}

\section{Introduction}

Fostering innovation has become a fundamental and necessary practice for companies to thrive and survive in today's globalized and competitive markets [1], [2]. Against this backdrop, employee-driven innovation emerges as increasingly important phenomenon [3]. This poses new challenges for innovation management, as the number of potentially valuable ideas usually exceeds an organization's capacity to put them in practice [4]. A recent global study among 1.600 executives found that selecting the right ideas was among the top three obstacles when investing in innovation [5]. Moreover, idea screening is a cognitively challenging task imbued with uncertainty, and a recent study among 330 managers found that organizations using information systems (IS) are more effective in screening collected ideas [6].

Alongside with the screening process itself, studies have shown that employee-driven innovation also means that the innovators need support from experienced colleagues that challenge and enrich their ideas [3], [7]-[9]. For such facilitators it is important to maintain an overview over existing ideas and initiatives within the company. As such, employeedriven innovation crucially depends on appropriate screening (i.e. evaluation, selection, and tracking) of ideas that innovators and facilitators carry out. Hence, the need for comprehensive, multi-attributive idea screening support throughout the whole innovation cycle has recently been brought forward [6], [10], [11]. For this reason, we raise the guiding research question: How can an information system facilitate the evaluation, selection, and tracking of ideas in employee-driven innovation?

Our contribution is threefold. Firstly, we elicit and illustrate the requirements for supporting idea screening and make a case of the employee-driven innovation practices in a software firm. Secondly, we identify a set of dimensions for screening ideas, namely purpose, value proposition, risk of adopting, risk of rejecting, scope, type, stage, communication strategy, resources, and participant roles. Through these empirically and theoretically grounded dimensions, we illustrate the multifaceted nature of ideas. Thirdly, we create an IT artifact and thus provide a proof of concept by showing how the Idea Screening Framework can be deployed in practice.

The remainder of this paper is structured as follows. We start by summarizing extant literature on employee-driven innovation and idea screening. The research method section then offers detailed insights into the applied method and illustrates how both literature and insights from our empirical study informed the design of the Idea Screening Framework. In the following sections, we describe in detail (1) what problem the Idea Screening Framework addresses, (2) what our proposed solution design looks like, and (3) how we implemented the Idea Screening Framework in an organization. We conclude with summarizing what lessons can be learned from the design and pointing to future research.

\section{Related Work}

Studies that informed our design are rooted in the emerging fields of digital, open, and employee-driven innovation as well as in the field of idea screening.

\subsection{Employee-driven Innovation}

Self-organizing networks of employees are a crucial driver for the development of complex and innovative digital technologies [1]. In an increasingly 
networked corporate environment, a differentiation strategy based on product, process, or business model innovation can be a key source of competitive advantage [1], [2]. In this context, the open innovation paradigm suggests to purposefully use both inflows and outflows of knowledge to accelerate internal innovation and expand the market for external innovation [12]. Thus, open innovation leads companies to replace centralized $\mathrm{R} \& \mathrm{D}$ departments with more network-based work structures [3, pp. 814]. Since traditional R\&D structures only enable selected experienced employees to work on ideas with a long-term impact, ever more companies facilitate collecting ideas from all sides [13]. Today's leading innovative companies encourage employees to act entrepreneurial within the confines of the organization, relying on its technical, financial, and professional resources [3]. Shrinking innovation cycles and new digital technologies make innovation more networked and employee-driven [14], [15] and increase the need of understanding the larger societal and economic impacts of this new paradigm of innovation [3], [9]. Employee-driven innovation is a new form of direct participation in which the employee takes the initiative to generate, develop, and implement ideas for innovative products [9], [16], [17]. Within every employee lies an innovative potential, which organizations need to foster and facilitate [18], [19]. Therefore, idea screening is an integral part of employee-driven innovation that requires according facilitation support.

\subsection{Idea Screening}

Employee-driven innovation offers new possibilities, but also poses new challenges to traditional ways of innovating in firms. This requires a revisit of established approaches for screening ideas, as this section illustrates.

Classical approaches for realizing value from IT investments, such as IT portfolio management [20] and benefits management [21], are helpful for integrating new digital technologies into the corporate strategy in a way that envisaged benefits are achieved (outside-in). However, screening large amounts of ideas from different sources in a short time requires a radical rethink of received strategic frameworks to manage IT projects [22]. To cite a prominent case, the British Petroleum (BP) company placed a public call for ideas to contain the infamous oil spill resulting from the Deepwater Horizon disaster in 2010. During this period BP received more than 35,000 ideas. However, lacking a way to quickly and accurately screen these ideas from diverse sources, frustration grew as BP seemed unable to select and implement solutions in time [4].
More recently, innovation platforms gain momentum as a promising means to fund and realize ideas from a crowd of internet users [23]. However, it remains a challenge to integrate these approaches with innovation initiatives in a corporate context [6], [10]. For instance, a recent study among 313 participants of an innovation community found that popular simple idea screening mechanisms based on thumbs up/down or 5-star rating are invalid and outperformed by more fine-granular, multi-attributive idea screening mechanisms [10]. In line with this, a study argues that idea screening mechanisms purely based on numeric scores tend to be too restrictive to reflect the value of human intuition [4]. However, practitioners tend to prefer simple scales based on benefit and risk, often neglecting more complex approaches [24]. Although recent studies acknowledge the potential of IT to better capture the complexity of idea screening, we know little yet about effective designs in practice [6].

Hence, we identify a research gap on how to provide comprehensive and multi-dimensional idea screening support for employee-driven innovation. Our goal with this paper is to (1) elicit the requirements of idea screening in the context of employee-driven innovation and (2) propose an Idea Screening Framework that fits the according work practices of various stakeholders.

\section{Research Method}

Since our goal is to extend human and organizational innovation capabilities by creating a new artifact, this paper follows the design science research (DSR) in information systems (IS) paradigm [25] and builds on the well-established DSR framework by Peffers et al. [26]. Hence, it is structured along six generic DSR activities: 1) problem identifycation, 2) objectives of a solution, 3) design \& development, 4) demonstration, 5) evaluation, 6) communication. Activities 1-5 are described in respective sections, and activity 6 is the paper's aim.

Initially, we identified the problem relevance and motivation for an Idea Screening Framework from a two-year ethnographically informed empirical study [27] of innovation practices at a multinational European banking software provider. Relying on the identified problem scenarios and the above described literature, we developed an initial prototype using the scenario-based development method [28]. Next, we discussed the early prototype extensively in the research team and obtained feedback from key informants from practice, who viewed the addressed problem from various perspectives [29]. From these sessions we obtained helpful feedback, e.g. about different goals of managers and innovators with the system and were also able to develop and evaluate a 
working prototype. The following sections illustrate these steps in detail.

\subsection{Case Presentation}

Since the above described previous research suggests that idea screening is especially relevant in innovation processes that are employee-driven [3], involve the confluence of ideas from various sources [12], and deal with high degrees of complexity [7], we selected the case based on three criteria: 1) high activity of employee-driven innovation 2) high degree of collaboration and 3) high innovation complexity. This led us to a European software company.

Founded in the early 1990ies by a group of software engineers, the company rapidly grew to an international market leader in banking software. Until 2008's financial crisis increased the pressure to innovate and diversify its solution portfolio, the strategic focus of BITS was the development, distribution, and operation of its proprietary core banking system. The executive board became increasingly concerned that the product lifecycle of that system might have peaked, and initiated substantial investments in establishing an internal innovation management framework. In the following years, the strategic focus of BITS became the development of new products, services, and business models in collaboration with customers, external partners, and universities. In the last two years, the company grew from around 600 to more than 1400 employees in two development centers and seven subsidiaries worldwide.

\subsection{Case Data Collection}

In the first data collection phase (02/2013 $10 / 2013$ ), the study focused on the way employees communicate ideas across intersecting social worlds. The first author spent between 2-4 days a week onsite at the BITS headquarter and had access to an in-house workstation and intranet platforms. From there, the author conducted 32 semi-structured interviews to get an in-depth understanding of the focal phenomenon from a participant's perspective [30]. Executives provided an initial set of interview partners and we proceeded with snowball sampling, through the network of personal contacts [31, p. 200]. Questions addressed the participants' innovation practices when collaboratively developing ideas, whereat participants were required to use authentic examples of their own experience. In doing so, we were able to document in detail the information requirements of various stakeholders throughout the innovation process. The phase ended with writing an interim study report with a status quo analysis, which we discussed with BITS to inform about our findings and frame the next phase.
In the second data collection phase $(01 / 2014-$ $12 / 2014)$, the study focused on how BITS employees collaborate across geographically distributed locations. The first author continued to spend between 1-2 days a week onsite at the BITS headquarter, and additionally spent between a week in a row onsite at a remote subsidiaries of BITS, during which he interviewed additional 30 experts. Questions addressed the way employees organize and share information about their innovative ideas. We thoroughly analyzed online networking platforms regarding their actual and potential usage for innovation and elaborated a set of key use cases. Using multiple sources of evidence [29] and triangulating between 1) the primary data from the interviews, and 2) the collected secondary data we extracted from these platforms, we were able to draw a more detailed picture of the actual innovation practices. The second phase ended with a report of an early concept of the Idea Screening Framework that we discussed with BITS representatives to identify concrete actions to take in the next phase.

In the third and ongoing data collection phase (from $01 / 2015$ ), we developed an IT artifact as proof-ofconcept and deployed it in BITS' intranet. The IT artifact instantiates the previously defined Idea Screening Framework, and we conducted several workshops with BITS employees to evaluate the artifact's usefulness.

\subsection{Case Data Analysis}

We carried out the data analysis collaboratively relying mostly on interview transcripts, collected documentary material, and field reports. We met in a group of four researchers in weekly focus groups [32] to maintain a critical distance with the case company [33]. The interviews were recorded, transcribed, and processed using MAXQDA, where two researchers developed a codebook to facilitate joint analysis and increase confidence in the findings [34]. Two additional researchers carried out coding checks to ensure intercoder reliability and develop a shared conception of reflection [35], through which we identified problem scenarios and solution objectives.

\subsection{Structured Literature Analysis}

Parallel to the case data collection cycles, we conducted a structured literature analysis in which we followed the well-established framework by Vom Brocke et al. [36]. Hence, we conducted the five generic steps: 1) definition of review scope 2) conceptualization of topic 3) literature scope 4) literature analysis and synthesis 5) research agenda. Steps 1-3 followed from the field study in which we identified research topics and the scope, namely idea screening in employee-driven innovation. In step 4 we 
searched on Google Scholar and AIS electronic library for the keywords "digital-, employee-driven, and open innovation, innovation management, -practices, and roles, idea screening, -evaluation, -selection, assessment, and -tracking, balanced scorecard", selected 73 sources from reading the titles and abstracts, and synthesized the selected sources into an early version of the here presented Idea Screening Framework. We then framed the research agenda (step 5) by moving back and forth between data and literature, interrogating field material to check whether the data supported emerging claims, and whether literature helped us making sense of the empirics [37].

\section{Problem Identification and Solution Objective}

In this section, we illustrate in detail the problem understanding we obtained from the empirical study and illustrate the information requirements for the various stakeholders of the innovation process. The problem scenarios are stylized cases of observed recurring problems at the case company [28].

Problem Scenario 1 (Innovator wants to realize an idea): "Malcolm, a 25 year old recent university graduate and junior software engineer at BITS, recently had an idea for a mobile banking application for smart watches. He quickly sketches a few screens and discusses them with colleagues during a coffee break. Malcolm's colleagues are excited about the idea, but he is still unsure about its feasibility, since BITS does not have any experience with smart watch applications yet. Also, Malcolm does not have a wellestablished network in the company yet, so he asks his line manager for advice. The line manager is currently quite busy and tells Malcolm to ask Denis, an experienced business analyst, who has promoted a lot of ideas in the past. A bit doubtful, Malcolm reveals the idea to Denis, who generally likes it, but emphasizes the importance of elaborating a business plan, to see how the company can make money with the idea. Malcolm has never created a business plan, but is motivated to invest two weeks of his spare time and a lot of help from his peers to write one. Afterwards, Denis sends the business plan to Corinne, an innovation manager at BITS. Corinne knows by chance that another team already develops a prototype for such an application, which is very similar to Malcolm's idea. Malcolm is very frustrated to have spent that much effort in vain."

The key issues with this problem scenario are: Innovators do not fully understand the decision structures behind the innovation process of the company and lack an overview over existing ideas [7]. They need to invest substantial time in building a social coalition for their idea, which is difficult because different stakeholders have different information requirements, and they often lack the social capital to persuade advocates and sponsors [3]. Innovators further need guidance and orientation to ensure completeness and consistency of relevant criteria, and to ensure that all relevant stakeholders are involved [8].

Problem Scenario 2 (The Innovation Board selects ideas for funding): "Corinne organizes a meeting with the innovation board, a committee of experienced employees, in order to decide which ideas should receive funding. She also invites the employees to present their business plans. Some presentations are very technical, and the innovation board has a hard time fully understanding the idea and assessing the benefits and risks. This makes the evaluation very demanding. Some of the ideas are presented with the help of an elaborated prototype. In these cases the ideas are more comprehensible, but deciding to not fund these ideas is even harder for Corinne, because she knows that already a lot of work was invested in the idea. Many of the presented ideas look promising to her, but she knows that they can only provide funding to few of them because most of them do not fit into the strategy of the company. Moreover, the resources they can allocate are limited, because this year's strategy is to focus on implementing customer requirements. They have to rely on intuition to evaluate the ideas, as fully evaluating all ideas in these different representations would be too demanding and time consuming."

The key issues with this problem scenario are: There is often an abundance of ideas existing in a company [12], [38], and therefore idea screening is a time consuming and cognitively demanding task, because it is very hard to assess the potential value of an individual idea [39], given that ideas are often hard to compare with each other [3]. Moreover, companies are often held captive by customer requirements which consumes innovation resources [40], because most funding decisions are based on financial aspects. One drawback of screening models purely based on numeric scores is that they tend to be too rigid and neglect human reflection and experience [10].

Problem Scenario 3 (Innovation Manager wants to track ideas): "Corinne, a 38 year old now innovation manager and former product manager at BITS, has her monthly status meeting with the CEO. The CEO just came back from an IS conference and was intrigued by a talk about crypto currencies. She is convinced that crypto currencies will soon become a disruptive innovation in the banking industry, so she asks Corinne whether there already exist any related ideas in BITS. Corinne must acknowledge that she does not know. She has only recently taken over this position after the 
former innovation manager left the company. There is no idea repository and Corinne must now ask all responsible innovators for current status of all innovation projects she inherited. The innovators themselves are not satisfied with having to start explaining their ideas anew and often give Corinne snippy responses. Both the $\mathrm{CEO}$ and Corinne are frustrated that even the innovation management does not seem to know about all ideas within the company."

The key issues with this problem scenario are: It is very difficult to have an aggregated view over existing ideas [3] in order to detect strengths and weaknesses in the innovation process and compare the innovativeness of the company with other organizations [3]. After all, trends in technology are difficult to anticipate, as any innovation involves some degree of uncertainty [41].

From these problem statements, we identify that the solution objective of an Idea Screening Framework is to facilitate the evaluation, selection, and tracking of ideas in an organization. The Idea Screening Framework should on the one hand give innovators guidance through the innovation process by evaluating, selecting, and tracking ideas. Through a central idea repository, innovators should be able to evaluate ideas by submitting them in a semi-structured manner, focus on relevant criteria, find relevant experts, and obtain community feedback. Through this idea repository, innovators should also be able to select relevant ideas from a large pool and, thereby, get an overview and orientation of the existing innovation process. Entries in the idea repository should enable the innovator to track the status of his/her idea.

On the other hand, the Idea Screening Framework should also allow managers to evaluate, select, and track ideas in order to make informed decisions of innovation projects within the organization. Through an aggregated overview of the innovation process, managers should be able to detect weaknesses and strengths by evaluating ideas in different stages, and make micro and macro level analyses of ideas. Through a semi-structured set of criteria, managers should be able to compare ideas against each other and select the most promising ones for further funding. Again, entries in the idea repository should enable managers to track the status of ideas.

To conclude, the Idea Screening Framework should provide enough structure to adequately illustrate decision-relevant information for managers at the right level of detail and abstraction, but at the same time provide innovators with enough flexibility to allow for sufficient interpretive openness and ambiguity that matches creative ideas. If the framework was too rigid it would prevent complex ideas to emerge and only serve few managers for decision support [3], but innovators would not feed the system with the necessary data. However, if the framework was too loose, the process would become arbitrarily complex, ideas could not be compared with each other, and managers would not take the system seriously. Hence the Idea Screening Framework should fulfill the requirements of a boundary object and be both flexible and robust to develop a common understanding and maintain coherence across intersecting social worlds [42].

\section{Artifact Design and Development}

So far, we motivated the need for an Idea Screening Framework by illustrating the problem, along with its significance, and envisaging how a better solution could look like. In this section, we describe in detail the concepts behind the Idea Screening Framework and the functionality of the IT artifact we implemented.

\subsection{Dimensions}

Our literature and empirical analysis yielded the following dimensions that are important for screening ideas: Purpose, Value Proposition, Risk of Adopting, Risk of Rejecting, Scope, Type, Stage, Communication Strategy, Resources, and Participant Roles. As shown in figure 1 , these can be grouped into three categories.

\begin{tabular}{|c|c|c|c|}
\hline $\mathscr{0}$ & Pur & \multicolumn{2}{|c|}{ Value Proposition } \\
\hline$\frac{\pi}{2}$ & Risk of Adopting & \multicolumn{2}{|c|}{ Risk of Rejecting } \\
\hline \multirow{2}{*}{ 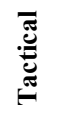 } & Scope & Type & Stage \\
\hline & \multicolumn{3}{|c|}{ Communication Strategy } \\
\hline 离 & \multicolumn{2}{|c|}{ Resources } & Participant Roles \\
\hline
\end{tabular}

Figure 1 - Dimensions of the Idea Screening Framework

Strategic dimensions are mostly important for executives to make a strategic decisions regarding of whether or not the idea should be pursued. For this effort, it is necessary to make assumptions about the benefit (which is incorporated in the Purpose and Value Proposition dimension) and risk of the idea. This is also important for potential collaborators, and customers to have a precise definition of the idea's core selling point.

Tactical dimensions are mostly important for the idea owners and innovation managers to have an overview about the status and next steps of an idea or all managed ideas.

Operational dimensions are especially helpful for facilitators and the innovators themselves to carry the idea further step by step. 
Purpose (why do we want to innovate?): Defining the purpose of an innovation helps to better understand the direction in which we are moving and the kind of benefits we can expect from moving into that direction. It facilitates the creation and recognition of links between the organizational strategy and the idea [43]. Ultimately, any IT innovation should create a clear business benefit.

The different reasons to innovate identified during our research can be encompassed by four different attributes. Financial Growth \& Profit aims at increasing revenue or market share, winning new customers, selling more products or licenses, or entering new markets [40]. One interviewee stated "it would be more interesting to make money from this innovation. That would be my main goal." Competitive Advantage aims at putting the organization ahead of competitors or preventing it from falling behind, for instance through achieving knowledge leadership, providing distinctive quality, or gaining the agility to profit from new opportunities [2]. One interviewee stated "if you have a complicated IT architecture, then your ability to move is like having lead weights on your feet". Efficiency Gain aims at doing the existing business faster and with fewer resources than now, for instance through improving communication efficiency, reducing delivery time, and increasing the input/output production ratio. Customer or employee satisfaction has the purpose to increase the satisfaction provided to end users, whether they are inside or outside the organization [3]. Such innovations contribute to the creation of a compelling place to work and deal with sources of customer frustration.

Value Proposition (what value does the innovation deliver to the customer?): This dimensions helps to identify the benefits that the innovation brings to the customer, and implicitly, the customer problems and needs that the innovation satisfies. This is important for the customer to determine whether or not to do business with the company. The attributes of this dimensions are derived from the business model canvas [44].

Newness satisfies a new set of needs the customer did not perceive before. For instance, these days smart watches may fall into this category. Performance improves the perceived usefulness of the existing features of a product or service. Customization adapts a product or service to the specific needs of the customer, such as customized or co-created products. Getting the job done means that the value resides simply in helping customers to accomplish their goals by providing a platform so they can run their business according to their needs. Design offers an outstanding and appealing design and creates value through aesthetics and ease of use. Brand/Status provides value by association with a specific brand with a certain social status. Price provides value through offering similar value than competitors, but at lower cost. Cost Reduction helps customers to reduce their cost, e.g. through self-service systems. Risk reduction reduces the risk of doing business, for instance through IT audits. Accessibility provides value by making the product accessible to customers who previously did not have access. Convenience/Usability provides value by making a product or service more convenient or easier to use, such as mobile banking apps.

Risks of Adopting (what risks do we face when doing the innovation?): This dimension refers to how the changes produced by the adoption of an innovation could negatively influence the organization and its environment. This is relevant for screening ideas because it helps to explore the scenarios that could result from adopting the innovation [45].

Monetary risks are financial risks of adopting the innovation. For instance, the actually needed resources may exceed the planned available resources due to poor project management or unforeseen factors such as changing requirements. Non-monetary risks cannot be measured in financial figures. For example, changes induced by the innovation may negatively impact some of the stakeholders, or the company may become dependent on a used technology and face lock-in effects.

Risks of Rejecting (what risks do we face when not doing the innovation?): This dimension refers to how the rejection of an innovation could affect the organization and its environment. This is relevant for screening ideas because it helps to explore the scenarios that could result from not innovating [45]. Monetary risks are financial risks of rejecting the innovation. For instance, the organization may miss potential profits (opportunity cost), or even have to pay fees and penalties when falling behind regulatory requirements. Non-monetary risks are risks of rejecting the innovation that cannot measured in financial figures, such as falling behind a competitor or negative reputation that results from being an innovation laggard [45].

Scope (whom do we innovate for?): This dimension refers to the target group of the innovation endeavors, which can either be internal or external [1]. This dimension can provide awareness about the balance of the innovation efforts made by the organization internally and externally. External innovations would encompass all products, processes, and services developed for customers outside the organization; while internal innovations comprise the innovations developed to be used within the organization. 
Type (what type of innovation do we do?): Considering the type of innovation is important because different types of innovation require different managerial approaches [46]. Recognizing and selecting the correct approach is vital for the success of the idea. Incremental innovation describes smaller incremental improvements on existing products, processes, or business models. Radical innovation refers to the creation of breakthrough products, processes, or business models with novel and unique characteristics, which often leads to a complete replacement of the previous working model [47]. Disruptive innovation encompasses those innovations that transform a product or service in a way that the market does not expect, usually aiming at a new group of consumers. This may involve the downgrading of the product to make it more accessible to customers that would not have afforded it otherwise. For instance, Henry Ford created a disruptive innovation when he took the existing idea of luxurious handcrafted cars which where only accessible to the higher class, and created factory made cheap generic automobiles accessible to the middle class [48]. It is important to note that here, the type of innovation, reflects the inner view of the organization (i.e. is the innovation incremental, radical, or disruptive for the organization), not the market view.

Stage (what is the maturity level of the idea?): Awareness about the maturity level of the ideas is important because it helps to identify what has already been done, what tasks are currently important, and what are the next steps. Identifying the stages of the innovation process is necessary for proper idea screening [4]. A five stage innovation process described by Desouza [3] serves as a base for this dimension. The process starts with the Idea Generation \& Mobilization stage, where novel ideas are brainstormed from the daily business and informally set in motion, before they become discussable projects competing for funding in the Advocating \& Screening stage. Here, idea owners advocate for the idea and build social coalitions, while managers are concerned with allocating resources to the most promising ideas. The funnel gradually narrows down in the Experimentation stage where innovators explore solution possibilities and constrain the possible solution stage by creating prototypes. Afterwards, the organization is concerned with turning the idea from concept to solution and developing a marketing plan in the Commercialization stage. Eventually, in the Diffusion and Implementation stage the company seeks to push the idea to the farthest corners of the market and show customers how to use the new product or service successfully.
Communication Strategy (how is the innovation introduced?): This dimension covers the way the idea is implemented in the target organization. Not all ideas are introduced to the world in the same manner, and the way we introduce a new idea may have a significant impact on its subsequent success. This success depends on different factors such as resistance caused by attachment to existing tools, learning curves, or perceived low value provided to individual adopters in the beginning that only increases with the size of the adoption network [49]. Awareness of this Dimension can help to determine if and how an idea should be implemented at a given moment [50] .

A Big Bang communication strategy introduces the innovation to the world all at once. A Pilot communication strategy introduced the idea at small scale in order to evaluate its performance before introducing it at full scale. The pilot is tested by a small group of users at first, and the innovation is released to the world after evaluating its success. A Phase communication strategy introduces the innovation to the world in phases, each phase taking place at a different time. Only the current phase of the idea is communicated to the world, but not the next steps.

Resources (what resources do we need to carry out the innovation?): This dimension is important for screening ideas because feasibility analyses prior to taking ideas forward are crucial. Not considering technical, financial, market, and human resource aspects before starting to realize an idea could result in project failure or serious losses. A good understanding of the innovation capabilities of the organization is crucial to determine which ideas it can realize and which ones it simply cannot afford [48]. The attributes of this dimensions are extracted from [40]. Human resources refer to manpower required for carrying out the innovation, typically the number of project team members. Equipment refers to physical or digital instruments required for carrying out the innovation, such as IT equipment (hardware or software), building infrastructure, tools, or vehicles. Financial resources refer to the budget that is necessary to carry out the innovation, such as initial investment. Intellectual resources refer to know how that is necessary to carry out the innovation, such as technical, organizational, or business knowledge.

Participant Roles (who is involved in the innovation?): Several studies focus on the identification and categorization of different roles relevant for innovation [51], [52]. Some authors use the roles of idea generator, idea champion, orchestrator, and devil's advocate [51], while others define the roles as product champion, gatekeeper, sponsor, business innovator, technical innovator, and 
promoter [52]. Our study also revealed the importance of different stakeholder roles in the innovation process at BITS, and we consolidated these findings with the literature to derive the following six attributes in which the participant roles fall.

Customers are clients involved in the innovation process, such as clients giving input for an idea are acting as a source of ideas. Effectuators take ownership of an idea and are the ones who are in charge of carrying the idea through the different innovation process phases [53]. They advocate for the idea, request funding, and are involved in the development of the idea. Technical advisors possess technical expertise in the relevant field and provide detailed technical information and advice about the idea, for example about the technical feasibility of the idea or appropriate technologies to realize it [52]. Business advisors possess more deep knowledge on the business aspects around the idea, know the customer or the market well, and thereby provide financial or strategic advise for turning the idea into a profitable solution [52]. External partners are collaborators from outside the organization that are involved in realizing the idea, such as technology partners, implementation partners, or training partners [2]. Sponsors, such as innovation boards, incubator companies, or venture capitalists [52], can provide the financial resources that are necessary to carry out the idea.

\subsection{IT Artifact}

We built the Idea Screening Framework as web application. The artifact functions as a plug-in for the BITS intranet, which means that employees could already use and test the system.

The workflow is structured as follows. Whenever a new idea emerges, the idea owner can add a new idea with a title, a short description, and keywords. At this stage, the idea automatically has the Stage value "idea generation and mobilization" and the other dimensions are optional fields. The idea owner can choose whether the idea is private to some users or publicly displayed and the system suggests some experts for the Participant Roles dimension based on entered keywords. Users can then comment and rate the idea. If and when the idea owner wants to further pursue the idea, he sends a request for promotion to the "advocacy and screening" Stage. An idea evaluator, who is typically an innovation manager, then makes an assessment of the idea in an innovation board meeting. Here, the dimensions Purpose, Value Proposition, Scope, and Type are mandatory fields that guide the evaluation, whereat the idea evaluators can either fill in the values themselves or request further information from the idea owner. After this activity, the idea evaluators decide on whether to accept or reject the idea at this stage of the process. If the idea is accepted, the idea owner can further refine the idea and elaborate especially in the Resources and Participant Roles dimensions, which are now mandatory at this stage of the process. Here, the Idea Screening Framework guides the idea owner with clearly formulating the necessary criteria for a business plan. The idea owner can then send another request to the idea evaluator for promoting the idea to the "experimentation" Stage. In this case, the idea evaluator makes another assessment of the idea based on the dimensions Participant Roles, Resources, Risk of Adopting, and Risk of Rejecting and decides in an executive board meeting on whether and how many resources to allocate for "experimentation". The idea owner can now publish information regarding the idea on the idea page and discuss issues with facilitators. This also allows idea evaluators to track progress and generates useful documentation for marketing \& sales personnel when the idea proceeds to the "commercialization" Stage and a marketing plan needs to be developed. Modifications are historicized to facilitate back tracking of an idea's development. Through this iterative workflow, the IT Artifact limits the complexity of the Idea Screening Framework. BITS representatives gave positive feedback for this aspect in the evaluation workshops.

\section{Demonstration and Evaluation}

We demonstrated the artifact in several workshops with experts at BITS. This helped us to validate the Idea Screening Framework's usefulness and usability, and to refine its dimensions or include additional ones. For instance, managers would point to the need for better classification of the risk dimension, including parameters that reflect the degree of intensity (e.g. low, medium, high), or further distinguishing the financial figures. Additionally, we conducted proof-of-concept workshops where we used a printed version of the Idea Screening Framework to categorize 10 existing ideas that were in progress at BITS at that time. Afterwards we implemented a click through prototype to test how users would react to the system. The test users were very satisfied with the functionality to select from large amounts of ideas, compare them against each other, and make an aggregated macro level analysis of all ideas in the different innovation process phases. Since the initial flat representation of the Idea Screening Framework was perceived as complex, we grouped the dimensions into categories (strategic, tactical, operational).

This paper reports on a prototype implementation. The complete implementation and evaluation of the system will be subject of further work. We propose to evaluate the Idea Screening Framework against the above described problem scenarios. In various 
workshops, we interviewed participants whether the prototype would be useful and usable to improve the described problems, confirming that the screening dimensions were valid and complete. In these workshops, it came evident that the Idea Screening Framework needs to find the right degree of complexity in order to allow various stakeholders express their different views in the system. The criteria for a qualitative evaluation of the system are number of successfully implemented ideas, quality of ideas, and satisfaction with the system when screening ideas.

\section{Conclusions and Future Work}

As employee-driven innovation becomes more widespread, appropriate screening of large amounts of ideas becomes more crucial for firms. Organizations tend to generate more ideas than they can actually implement, and these ideas compete against each other for resources [3], [5].

Against this backdrop, screening should not only be seen as a single phase of the innovation process, but something that should be considered throughout the whole process. However, extant screening procedures are either too unstructured to facilitate evaluation, selection, and tracking, or too structured to capture complex ideas [10].

In this paper, we design an Idea Screening Framework and demonstrate how it can support the evaluation, selection, and tracking of ideas, which are crucial for employee-driven innovation. Our key design lesson learnt is that an information system that supports idea screening needs to be a servant of two masters. On one hand, it needs to provide decision support by illustrating the relevant information for deciders in the right level of abstraction. In that regard, the Idea Screening Framework needs to be a precise model of an idea that provides unambiguous decisionrelevant information. But at the same time, the Idea Screening Framework needs to provide a sufficient level of ambiguity to allow for interpretive flexibility and serve as boundary object across intersecting social worlds [42]. We contribute to extant literature by illustrating the dual role of idea screening and putting it into the work context of employee-driven innovation.

Companies may implement this Idea Screening Framework and customize the specified dimensions and attributes according to their specific needs. For instance, a company could configure the bounds of what constitutes a high financial profit or where the line between high and medium risk lies, and specify the available participant roles.

This research has to be seen in the light of its limitations. We developed the Idea Screening Framework in close collaboration with a single company, and further work is necessary to test whether the proposed design is useful in other contexts, too.

\section{Acknowledgments}

We thank the employees of BITS for their openness and support. We also thank our ambitious students for contributing to this study (in alphabetical order): David Bolli, Fabian Gautschi, Daniel Oettli, Luis Pena, and Annatina Vinzens.

\section{References}

[1] H. W. Chesbrough, Open innovation: The new imperative for creating and profiting from technology. Harvard Business Press, 2003.

[2] J. Tidd and J. Bessant, Managing innovation: integrating technological, market and organizational change. Wiley. com, 2011.

[3] K. C. Desouza, Intrapreneurship: managing ideas within your organization. University of Toronto Press, 2011.

[4] J. Lindič, P. Baloh, V. M. Ribière, and K. C. Desouza, "Deploying information technologies for organizational innovation.," International Journal of Information Management, vol. 31, no. 2, pp. 183-188, 2011.

[5] J. P. Andrew, J. Manget, D. C. Michael, A. Taylor, and H. Zablit, "Innovation 2010: A return to prominence-and the emergence of a new world order," Boston, MA: Boston Consulting Group, 2010.

[6] T. Schulze, M. Indulska, D. Geiger, and A. Korthaus, "Idea Assessment in Open Innovation: A State of Practice," ECIS 2012 Proceedings, May 2012.

[7] K. Fichter, "Innovation communities: the role of networks of promotors in Open Innovation," $R \& d$ Management, vol. 39, no. 4, pp. 357-371, 2009.

[8] M. Tortoriello, B. McEvily, and D. Krackhardt, "Being a Catalyst of Innovation: The Role of Knowledge Diversity and Network Closure," Organization Science, 2014.

[9] S. Høyrup, C. Hasse, M. Bonnafous-Boucher, K. Møller, and M. Lotz, Employee-driven innovation: A new approach. Palgrave Macmillan, 2012.

[10] C. Riedl, I. Blohm, J. M. Leimeister, and H. Krcmar, "Rating scales for collective intelligence in innovation communities," in ICIS 2010 Proceedings, 2010.

[11] L. J. Gressgard, O. Amundsen, T. Aasen, and K. Hansen, "Use of information and communication technology to support employee-driven innovation in organizations: a knowledge management perspective," Journal of Knowledge Management, vol. 18, no. 4, pp. 633-650, 2014.

[12] H. Chesbrough, W. Vanhaverbeke, and J. West, "Open innovation: a new paradigm for understanding industrial innovation," Open innovation: researching a new paradigm, pp. 1-12, 2005.

[13] A.-K. Neyer, A. C. Bullinger, and K. M. Moeslein, "Integrating inside and outside innovators: a sociotechnical systems perspective," $R \& D$ Management, vol. 39, no. 4, pp. 410-419, 2009.

[14] R. F. Ciriello and A. Richter, "Idea Hubs as Nexus of Collective Creativity in Digital Innovation," in ICIS2015 Proceedings. 
[15] A. G. Robinson and D. M. Schroeder, The Idea-driven Organization: Unlocking the Power in Bottom-up Ideas. Berrett-Koehler Publishers, 2014.

[16] P. Kesting and J. Ulhøi, "Employee-driven innovation: extending the license to foster innovation," Management Decision, vol. 48, no. 1, pp. 65-84, Feb. 2010.

[17] R. F. Ciriello, A. Richter, and Schwabe, Gerhard, "PowerPoint Use and Misuse in Digital Innovation," in ECIS2015 Proceedings.

[18] M. Kristiansen and J. Bloch-Poulsen, "Employee driven innovation in team (EDIT)-Innovative potential, dialogue, and dissensus," International Journal of Action Research, vol. 6, no. 2-3, pp. 155-195, 2010.

[19] A. B. Hargadon and B. A. Bechky, "When collections of creatives become creative collectives: A field study of problem solving at work," Organization Science, vol. 17, no. 4, pp. 484-500, 2006.

[20] J. Peppard and J. Ward, "Beyond strategic information systems: towards an IS capability," The Journal of Strategic Information Systems, vol. 13, no. 2, pp. 167-194, 2004.

[21] J. Peppard, J. Ward, and E. Daniel, "Managing the realization of business benefits from IT investments," MIS Quarterly Executive, vol. 6, no. 1, pp. 1-11, 2007.

[22] Y. Yoo, O. Henfridsson, and K. Lyytinen, "Research commentary-The new organizing logic of digital innovation: An agenda for information systems research," Information Systems Research, vol. 21, no. 4, pp. 724-735, 2010.

[23] E. Mollick, "The dynamics of crowdfunding: An exploratory study," Journal of Business Venturing, vol. 29, no. 1, pp. 1-16, 2014.

[24] S. Schönwälder, Portfoliomanagement für betriebliche Informationssysteme. Springer-Verlag, 2013.

[25] A. R. Hevner, S. T. March, J. Park, and S. Ram, "Design science in information systems research," MIS quarterly, vol. 28, no. 1, pp. 75-105, 2004.

[26] K. Peffers, T. Tuunanen, M. A. Rothenberger, and S. Chatterjee, "A design science research methodology for information systems research," Journal of management information systems, vol. 24, no. 3, pp. 45-77, 2007.

[27] H. Robinson, J. Segal, and H. Sharp, "Ethnographically-informed empirical studies of software practice," Information and Software Technology, vol. 49, no. 6, pp. 540-551, 2007.

[28] M. B. Rosson and J. J. M. Carroll, Usability engineering [electronic resource]: scenario-based development of human-computer interaction. Morgan Kaufmann, 2002.

[29] R. K. Yin, Case study research: Design and methods, vol. 5. Sage, 2009.

[30] M. B. Miles and A. M. Huberman, Qualitative data analysis: An expanded sourcebook. Sage, 1994.

[31] R. A. Stebbins, Exploratory research in the social sciences, vol. 48. Sage, 2001.

[32] R. A. Krueger, Focus groups: A practical guide for applied research. Sage, 2009.

[33] F. Wickson, A. L. Carew, and A. W. Russell, "Transdisciplinary research: characteristics, quandaries and quality," Futures, vol. 38, no. 9, pp. 1046-1059, Nov. 2006.

[34] J. T. DeCuir-Gunby, P. L. Marshall, and A. W. McCulloch, "Developing and using a codebook for the analysis of interview data" Field Methods, 23-2, 136-155, 2011.

[35] C. Weston, T. Gandell, J. Beauchamp, L. McAlpine, C. Wiseman, and C. Beauchamp, "Analyzing interview data: The development and evolution of a coding system," Qualitative Sociology, vol. 24, no. 3, pp. 381-400, 2001.

[36] J. vom Brocke, A. Simons, B. Niehaves, K. Reimer, R. Plattfaut, and A. Cleven, "Reconstructing the giant: On the importance of rigour in documenting the literature search process.," ECIS 2009 Proceedings, Jan. 2009.

[37] D. Yanow and P. Schwartz-Shea, Interpretation and method: Empirical research methods and the interpretive turn. ME Sharpe, 2013.

[38] T. Gorschek, S. Fricker, K. Palm, and S. A. Kunsman, "A lightweight innovation process for software-intensive product development," IEEE software, vol. 27, no. 1, p. 37, 2010.

[39] G. Jouret, "Inside Cisco's Search for the Next Big Idea," Harvard Business Review. [Online]. Available: https://hbr.org/2009/09/inside-ciscos-search-for-the-next-bigidea. [Accessed: 05-Jun-2015].

[40] C. Christensen, The innovator's dilemma: when new technologies cause great firms to fail. Harvard Business Press, 1997.

[41] H. Jalonen and A. Lehtonen, "Uncertainty in the innovation process," Proceedings of ECIE, 2011.

[42] S. L. Star and J. R. Griesemer, "Institutional ecology, translations and boundary objects: Amateurs and professionals in Berkeley's Museum of Vertebrate Zoology, 1907-39," Social studies of science, vol. 19, no. 3, pp. 387420, 1989.

[43] N. Gama, M. M. da Silva, and J. Ataíde, "Innovation scorecard: a balanced scorecard for measuring the value added by innovation," in Digital Enterprise Technology, Springer, 2007, pp. 417-424.

[44] A. Osterwalder and Y. Pigneur, "Business Model Generation: A Handbook For Visionaries, Game Changers, And Challengers," 2010.

[45] E. Rogers, Diffusion of innovations. Free press, 2010.

[46] G. Trauffler, "Strategic management of discontinuous technologies and radical innovation," ETH Zürich, 2005.

[47] R. Stringer, "How to manage radical innovation," California Management Review, 42, no. 4, pp. 70-88, 2000.

[48] C. M. Christensen and M. E. Raynor, The innovators solution: Creating and sustaining successful growth. Harvard Business Press, 2003.

[49] R. G. Fichman, "Real options and IT platform adoption: Implications for theory and practice," Information Systems Research, vol. 15, no. 2, pp. 132-154, 2004.

[50] K. D. Eason, Information technology and organisational change. CRC Press, 2005.

[51] M. Meyer, "Innovation roles: from souls of fire to devil's advocates," Journal of Business Communication, vol. 37, no. 4, pp. 328-347, 2000.

[52] A. K. Chakrabarti and J. Hauschildt, "The division of labour in innovation management," $R \& D$ Management, vol. 19, no. 2, pp. 161-171, 1989.

[53] S. D. Sarasvathy, "Causation and effectuation: Toward a theoretical shift from economic inevitability to entrepreneurial contingency," Academy of management Review, vol. 26, no. 2, pp. 243-263, 2001. 
